\title{
Innovation as a factor in increasing the efficiency of soybean production in the Amur Region
}

\author{
Olga Shchegorets ${ }^{1,{ }^{*}}$, Pavel Tikhonchuk ${ }^{1}$, Ivan Bumbar ${ }^{1}$, and Andrey Yakimenko ${ }^{1}$ \\ ${ }^{1}$ Far Eastern State Agrarian University, Russia
}

\begin{abstract}
Soybean is a diversification culture of the agricultural industry of the Russian Federation. Since the beginning of the 21st century, the production of this crop has increased 12 times, a 'soy belt' is being created, experience in the crop cultivation is being accumulated in the regions. The increase in the gross yield of soybeans is caused by the expansion of sown areas, the yield remains below the world average. The task of the Russian soybean community is to bring the level of production to 7 million tons by increasing the yield of soybeans, while introducing modern innovations: highly productive varieties, progressive technologies, agricultural practices, compliance with the farming system. The paper considers soybeans as a backbone culture of the agricultural industry of the Amur Region. This region is the main producer of soybeans in the country. The paper presents an analysis of the production of this crop over a hundredyear period. At present, the volume of soybean production has reached 1 million tons, with a yield of $1.3 \mathrm{t} / \mathrm{ha}$. The reasons for low productivity are revealed and real possibilities of obtaining resource yields of 3 and more tons per hectare are presented, which is confirmed by the indicators of scientific research and the results of advanced agricultural enterprises.
\end{abstract}

\section{Introduction}

Soybean is one of the three most important crops of modern agriculture, which solves the problem of protein deficiency for the growing population of the planet. In the twentieth century, it significantly changed the distribution area, which more and more extends to the north of the temperate zone, to the permafrost zone. The culture is cultivated in almost 100 countries. The range of soybean yields in the world varies from 0.5 to $9 \mathrm{t} / \mathrm{ha}$, the average is $2.5 \mathrm{t} / \mathrm{ha}$. The culture is flexible, at the same time very specific, the level of productivity is determined not only by natural and climatic resources, but also by the high genetic potential of modern varieties, progressive farming systems, innovative technologies and technical means.

Three hundred seventy five years ago, at the time of the great geographical discoveries, Russian explorers were the first Europeans to get acquainted with soybeans cultivated along the Amur by the aboriginal population. Three centuries later, the soybean production

\footnotetext{
* Corresponding author: olga.viktorovna.rus@yandex.ru
} 
industry began to form in the Russian Far East, having gone through difficult and contradictory periods: denials - "soybean is an unpromising crop", at the same time, early ripening highly productive varieties and technologies were created, the culture successfully fit into the structure of crops; drop in production in the post-perestroika period; 2010 is a time of recognition - "soybean is a priority crop in Russia". Fig. 1 shows the dynamics and trend line of soybean production in the Far East over 100 years [1].

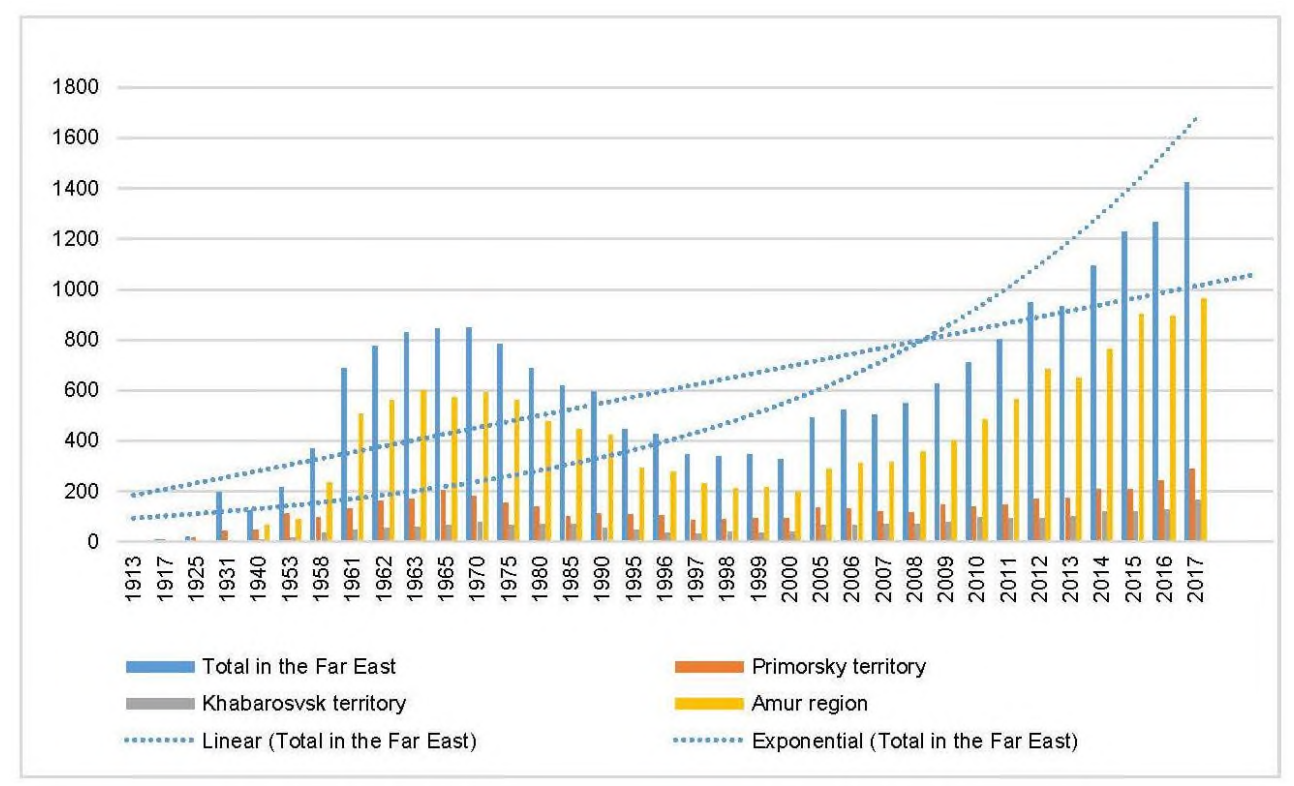

Fig. 1. Dynamics of soybean areas in the Far East over 100 years, thousand hectares.

Nowadays, soybean production in Russia is a dynamically developing industry. In the 21 st century, the production of soybeans increased 12 times, a 'soy belt' is being created, and experience in the cultivation of a diversified culture is being accumulated in the regions of Russia. The average yield of soybeans is $1.5 \mathrm{t} / \mathrm{ha}$, some regions have reached the level of $2.5 \mathrm{t} / \mathrm{ha}$. In 2019, the volume of soybean production amounted to 4.3 million tons (less than $2 \%$ of the global volume), the same amount is its import. The task of the soybean production of the Russian Federation: to raise the yield to 2-3 t/ha, to bring production to 7 million tons in 2020 [2], to meet the needs of the country, to occupy the niche of environmentally friendly soybeans in the international market.

In the Amur region, soybeans are a backbone agricultural culture. Throughout the history of the soybean, the region has been the main soybean producer in the country. The gross harvest of sowing grain reached one million tons (2014). Soybean is a crop of federal significance, while the region's share in the structure of state production has decreased from 75 to 20 percent. With a large land of the Amur Region, an extensive development path dominates, an increase in soybean areas is caused by the introduction of fallow lands and a reduction in the area for grain crops.

The goal set by the Ministry of Agriculture of the Russian Federation for scientists and agricultural producers of the Amur Region is to double the production of soybeans, to raise the yield to $2-2.5 \mathrm{t} / \mathrm{ha}$. An increase in the efficiency of soybean production is possible when solving the following problems: diversifying the crop production industry, observing the factors of the farming system, introducing selection, technical and technological innovations in combination with the advanced experience of Amur farmers. 


\section{Materials and Methods}

In these studies, methods of analysis, comparison and synthesis were used. The dynamics of soybean production (area, yield, gross yield) in Russia, the Far East, the Amur Region has been studied over a hundred-year period since the beginning of the formation of the industrial sector of soybean production. The resource productivity of breeding varieties in the conditions of the Amur Region is shown. A comparative analysis of the basic technology of soybean cultivation in the Amur Region and promising technologies of soybean cultivation is presented. An innovative method of assessing (forecasting) the duration of agricultural sowing and harvesting of soybeans, while providing production with seeding complexes and combine harvesters in the natural and climatic conditions of the Amur Region, was used.

\section{Results}

The main criterion for assessing the efficiency of crop production is yield. The yield of soybeans in the Amur region over the past 80 years has remained at the level of $0.5-1.3$ $\mathrm{t} / \mathrm{ha}$. At the same time, the history of early soybean production, the experience of advanced farms of different times, the indicators of state variety testing plots (SVTP) of the Amur Region demonstrate high yield rates - 3-5 t/ha (Table 1).

Table 1. Dynamics of yield and area of soybeans in the Amur Region.

\begin{tabular}{|c|c|c|c|c|c|c|c|c|c|c|c|c|c|}
\hline \multirow{4}{*}{$\begin{array}{c}\text { indicators } \\
\text { Yield, } \\
\text { t/ha }\end{array}$} & \multicolumn{13}{|c|}{ Years, yield in SVTP, in agricultural enterprises } \\
\hline & \multicolumn{2}{|c|}{$1935-1940$} & $\begin{array}{l}1961- \\
1970\end{array}$ & $\begin{array}{l}1976- \\
1980\end{array}$ & $\begin{array}{c}1981- \\
1985\end{array}$ & $\begin{array}{c}1986- \\
1990\end{array}$ & $\begin{array}{c}1991- \\
1995\end{array}$ & $\begin{array}{l}1996- \\
2000\end{array}$ & $\begin{array}{l}2001- \\
2005\end{array}$ & $\begin{array}{l}2006- \\
2010\end{array}$ & \multicolumn{2}{|c|}{$2010-2017$} & \multirow{2}{*}{$\begin{array}{l}\text { Projec } \\
t \text { for } \\
2025\end{array}$} \\
\hline & SVTP & \multicolumn{10}{|c|}{ average yield under production conditions } & $\begin{array}{c}\text { SVT } \\
\text { P }\end{array}$ & \\
\hline & 3.4 & $\begin{array}{l}2 . \\
3 \\
\end{array}$ & 0.55 & 0.65 & 0.81 & 0.98 & 0.78 & 0.74 & 0.78 & 0.97 & 1.27 & $3-5$ & 2 \\
\hline Area, th.ha. & & 60 & 600 & 495 & 449 & 424 & 368 & 228 & 254 & 374 & 850 & & \\
\hline
\end{tabular}

The growth of gross soybean production with a comparative analysis of yield and sown area (Table 1) shows that the method of extensive development of soybean production has been put on hold in the region for a long time. The implementation of the current task - to increase the yield to 2-2.5 t/ha, requires complex, innovative approaches, diversification of the crop growing industry, the introduction of agrotechnical innovations in combination with the best practices of Amur farmers, and compliance with the farming system.

In the modern world, the paradigm of agriculture is changing, traditional factors are coming to the fore: soil - the principles of careful management and preservation of its fertility; variety - determining the level of crop yield; biologized technologies are aimed at creating the most comfortable conditions for the formation of the production process of a culture, variety (varietal technology); obtaining environmentally friendly products; the use of modern, resource-saving agricultural technology, the preservation of a sustainable agrocoenosis.

With the transition to market relations, the state of the crop production industry has undergone great changes. In the absence of a government order, the growth of market demand for soybeans led to a significant change in the structure of sown areas in the Amur Region (Fig. 2). 


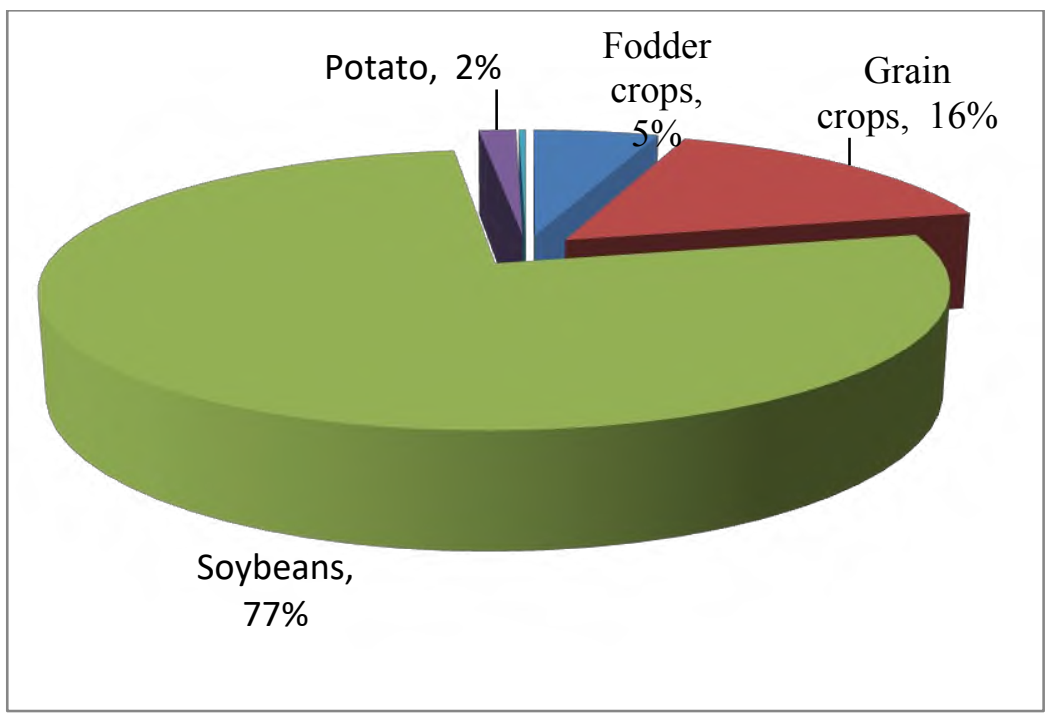

Fig.2. Structure of cultivated areas.

With the dominance of soybeans in the crop structure up to $80 \%$, it is impossible to observe the crop rotation. Monocultural orientation in field cultivation caused a complex of agrobiological, phytosanitary problems in the agrocoenosis, a drop in soil fertility, which is transformed into indicators of the economic order: an increase in the cost of means of protection, an increase in the cost of production, a decrease in the profitability of soybean production.

The share of soybeans in the structure of crop rotation must be reduced to $50 \%$ [3]. Soybeans, with a balanced crop structure, an excellent precursor for cereals, are the most important crop of agricultural biologization, leave behind more than $200 \mathrm{~kg} / \mathrm{ha}$ of biological nitrogen, thereby significantly reducing the cost of fertilizers, ensuring an increase in arable land productivity. To maintain biota, increase soil suppression, it is necessary to use green manure fallows, both from field crops and wild growing ones (weeds).

Diversification of the plant growing industry is the introduction of alternative crops that do not replace soybeans, but successfully complement it in a balanced crop rotation, such as hemp, flax, rapeseed. Textile crops were successfully cultivated in the Amur Region until the middle of the last century. Currently, these are economically profitable crops that are in market demand, included in the state program to support the production of importsubstituting crops. In the Far Eastern State Agrarian University, long-term studies of the cultivation of drug-free cannabis and oil flax have been carried out, and a positive result has been obtained as promising crops for cultivation $[4,5]$.

Crop rotation optimization, green manuring of soil are return innovations that are aimed at preserving soil fertility, increasing plant productivity, adhering to a scientifically grounded farming system, and increasing production efficiency.

In the Strategy for the Innovative Development of the Russian Agricultural Industry for the Period until 2020 [6], it is noted that in the agricultural industry of the Russian Federation, a significant part of production is based on outdated technological modes, which leads to the use of extensive technologies and non-compliance with agrotechnical requirements for growing crops.

In the Far East, soybeans are cultivated using the unified technology of continuous sowing of grain crops (basic technology). The technology is available, simple, has a minimum cost, does not imply carrying out agricultural practice during the growing season. The method of cultivating the culture proved itself in the difficult $90 \mathrm{~s}$. The technology is 
acceptable for the cultivation of early maturing single-stemmed varieties on floodplain soils, free from perennial weeds, and this is less than $10 \%$ of the structure of arable land in the region. The existing soybean technology does not provide an increase in productivity on meadow-chernozem soils, which are the most fertile in the Far East region and constitute the main share in the structure of arable land. But there is a drawback. They are heavy in composition - loamy and clayey, with low filtration and aeration, prone to waterlogging during the monsoon period. Up to $80 \%$ of soybean crops are located on these soils. Optimizing the water-air regime, taking into account the specific features of soybeans, is possible only when using the technology for row crops with a profiling surface.

The task of any technology is to create the most comfortable conditions for the culture in order to satisfy biological characteristics, to realize the genetic potential of the variety. It is necessary to change the technological mentality and introduce special soybean technologies. This is confirmed by the historical experience of the formation of the soybean production in the Amur Region. Russian settlers, accustomed to the scattered method of sowing grain, were amazed at the local farmers who grow soybeans in seedbeds, in rows, with inter-row weeding and hilling. It was a very labor intensive crop that they did not try to cultivate.

The Plan for the Development of Field Cultivation in the Russian Far East (1924) set the task: to combine the experience of three farming cultures into one economic system: East Asian, European, American. The industrial production of soybeans began with the early maturing, highly productive variety Amurskaya 41 (1931). Breeder V.A. Zolotnitsky, using the experience of the Manchus, developed row-crop agricultural technology for the cultivated varieties of soybeans [7]. Samples of soybean equipment were created: seeders, harrows, weeding machines, cultivators. At the Amur experimental station, the yield of soybeans was $3.4 \mathrm{t} / \mathrm{ha}$, in farm crops $-2.3 \mathrm{t} / \mathrm{ha}$ (Table 1, Fig. 3).
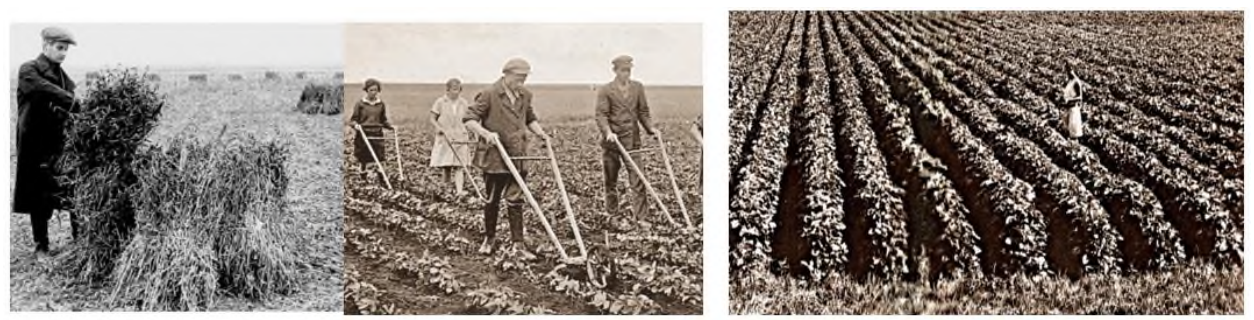

Fig. 3. The founder of soybean production in Russia V.A. Zolotnitsky, variety Amurskaya 41, development of soybean agricultural technology (Amur test field, 30s, XX century).

Expansion of areas for soybeans during the development of virgin lands when the area increased by 10 times (600 thousand hectares, Table 1$)$. Weak technical equipment of production led to a reduction in technology and a drop in yield to $0.55 \mathrm{t} / \mathrm{ha}$. A repeated attempt to cultivate soybeans as a row crop, including on the ridges, began during the period of the introduction of intensive technologies in the Amur region, which significantly increased the yield of soybeans [87]. Socio-economic processes of the post-perestroika period put on a hold an extensive path of development with the basic technology for a long time.

The implementation of the Century-old Plan for the Development of Field Cultivation in the Russian Far East remains relevant at the present time. It is the innovative processes in crop production, supported by public-private investments, that can bring the soybean industry to a highly efficient level, and increase the production of environmentally friendly Russian soybeans.

New varieties are one of the main innovations in agriculture. It is the variety that determines the level of yield, quality, and increases the competitiveness of production. At 
the Amur State Variety Testing Site, the traditions established at the Amur Test Field (TF) are preserved - soybeans are cultivated with a high culture of agriculture, row-crop technology. The yield of promising and regionalized varieties is 3-5 t/ha. In the region, more than 50 varieties have been zoned, varieties of foreign selection are cultivated with a yield of 3-5 t/ha, which in production conditions is realized only by $30 \%$ [3]. Highly commercial varieties on the market are varieties with a high content of protein in seeds more than $40 \%$, oils - not less than $20 \%$. The variety is able to materialize the genetic resources of productivity only in an ecologically favorable cultivation zone [9], with a technology that meets the requirements of culture biology, in compliance with the factors of the farming system (Fig. 4).
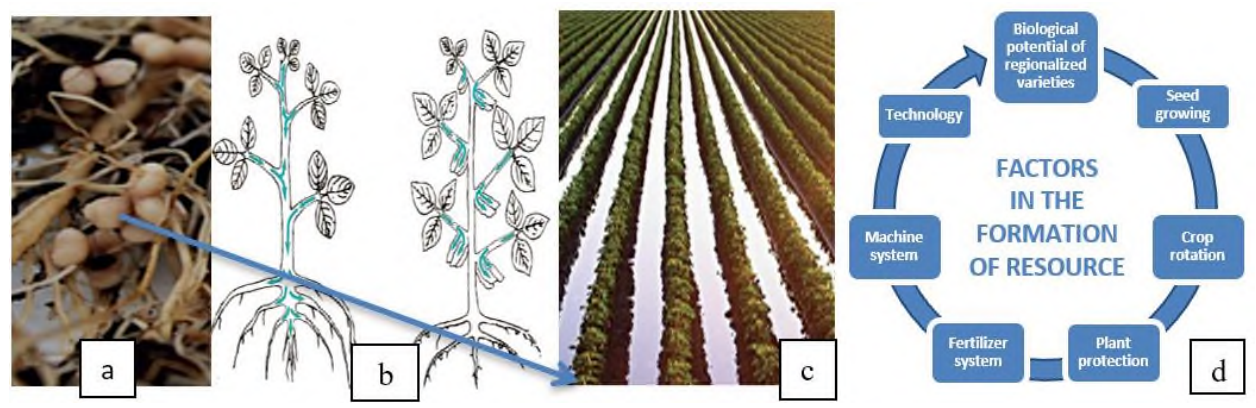

Fig. 4. Morphobiological and agrotechnical features of soybeans: a - root system and nitrogen-fixing nodules; $\mathrm{b}$ - local distribution of photosynthetic products; $\mathrm{c}$ - ridges of soybeans in a monsoon climate; $d$ - factors of the farming system (formation of resource yields).

Morphobiological and agrotechnical features of soybeans:

- $\quad$ soybeans are moisture-loving culture, while they do not tolerate waterlogging, flooding, because it has a symbiotic type of nutrition: mutualistic occurs only with good aeration of the soil, meeting the needs of soybeans in nitrogen up to $92 \%$ (Fig. 4, a). During the period of monsoon rains, with prolonged waterlogging up to flooding, as has been observed since 2014, the water-air regime unfavorable for nitrogen fixation is disturbed, the mutualistic symbiosis turns into parasitic, sharply reducing the productivity of soybeans. This is the main reason for the cultivation of soybeans on the profiling surface - ridges, seedbeds that carry out mini-reclamation, which is typical for the technology of soybean cultivation in the neighboring region - China (Fig. 4, c);

- heavy meadow-chernozem-like soils of the Amur Region (the main arable fund) have a large cultivation history, are clayey and loamy. During the period of monsoon rains, the soils become very waterlogged, compacted, which inhibits the development of strains, their activity reduces productivity, causing waterlogging of plants;

- soybeans have a weak competitive ability in relation to weeds. Inter-row cultivation destroys weeds, reducing the herbicidal load, increases aeration, stimulating nitrogen fixation, productivity;

- wide row sowing is favorable for photosynthetic productivity. Soybeans have the local distribution of the products of leaf photosynthesis to the beans, which are located in the axils with leaves alternately located on the stem (Fig. 4, b). If the leaf does not receive sufficient illumination with thickened crops or for other reasons - there is empty grain, abortion of beans, a decrease in plant productivity;

- the cultivation of soybeans as a row crop allows using stand management during the growing season - methods, means of managing the production process. This is a whole concept for increasing the productivity of soybeans, which is based on varietal agricultural technology to meet the biological requirements of soybeans, the formation of high yields, and marketing. This block of technology contributes to a 2 -fold increase in yield. 
The most important component of increasing the production of soybeans in the Amur Region is the introduction of innovations related to the reduction of the terms of sowing and harvesting crops [10]. With a long growing season of soybeans (up to 130 days), a short growing season of the Amur region, a relatively early onset of frost, snowfall, insufficient provision with seeding complexes and combines, the calendar sowing and harvesting periods are delayed. In some years, under all these circumstances, part of the crop remains under the snow.

The Far Eastern State Agrarian University developed a methodology for assessing the effectiveness of the timing of sowing and harvesting soybeans. The dynamics of the implementation of these technologies in the Amur Region is presented in the form of innovative analytical expressions (Table 2) and graphs (Fig. 5-8). Their use makes it possible to predict the course of sowing and harvesting, to determine the directions and operational reliability, and also allows a comparative analysis of the efficiency of the combine harvesters of various factories and manufacturers. This assessment is of practical interest for soybean breeders in terms of assessing the acquisition of modern technology.

Table 2. Analytical dependences of soybean sowing (2017 - 2019).

\begin{tabular}{|c|c|c|c|}
\hline Crop & Indicators & Year & Analytical expression \\
\hline Soybean & $\begin{array}{c}\text { Area, ha (y) } \\
\text { Number of } \\
\text { sowing days } \\
(\mathrm{x})\end{array}$ & 2018 & $\mathrm{y}=0.4977 \mathrm{x}^{4}-72.038 \mathrm{x}^{3}+3076 \mathrm{x}^{2}-17435 \mathrm{x}+20165$ \\
\cline { 3 - 5 } & & 2019 & $\mathrm{y}=-0.2013 \mathrm{x}^{4}+18.5 \mathrm{x}^{3}-727.7 \mathrm{x}^{2}+33702 \mathrm{x}-52408$ \\
\hline
\end{tabular}

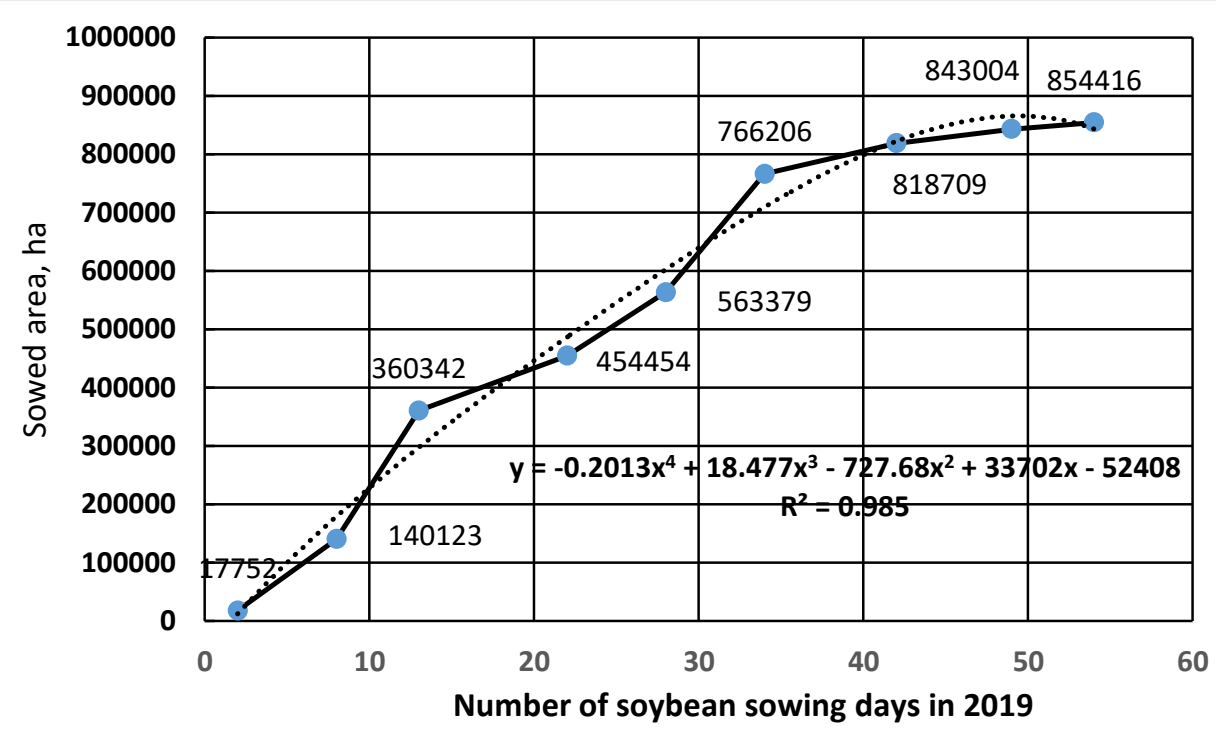

Fig. 5. The size of the sown area of soybeans, ha (2019). 
The analysis of harvesting shows a significant violation (up to 50 days, Fig. 7, 8) of the optimal agro-terms, which leads to crop losses (Fig. 8)

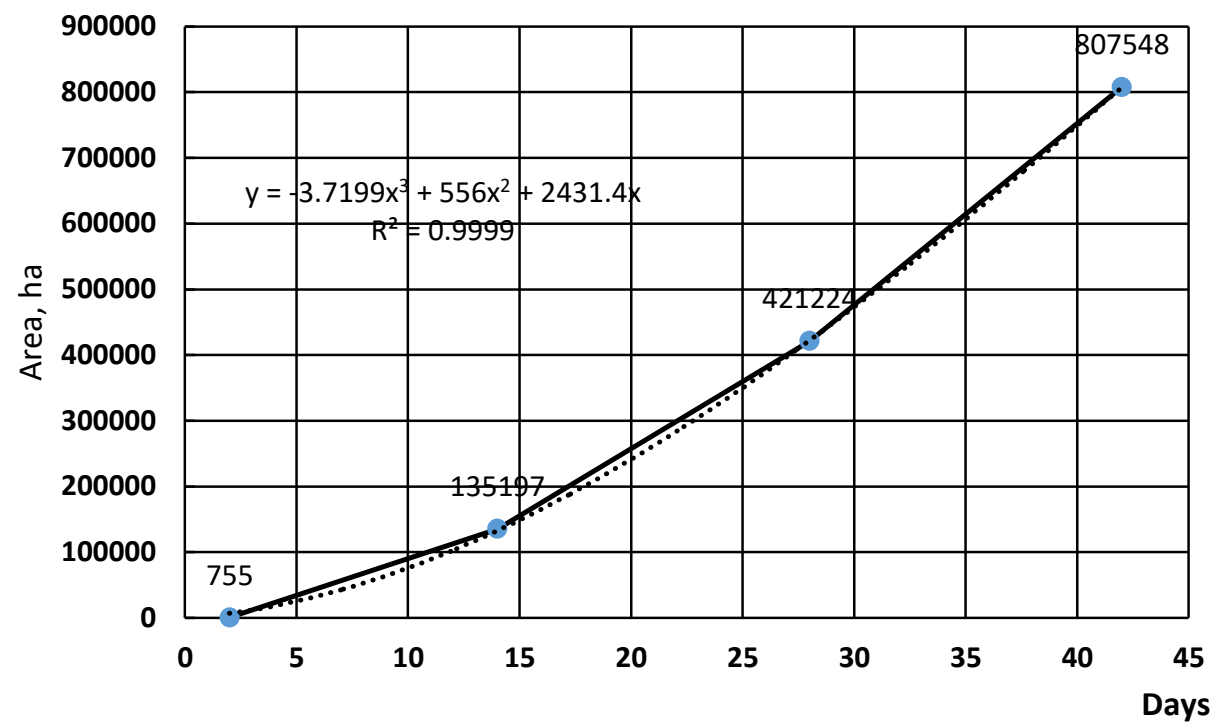

Fig. 6. The size of the harvested area of soybeans by days of harvest, ha (2017).

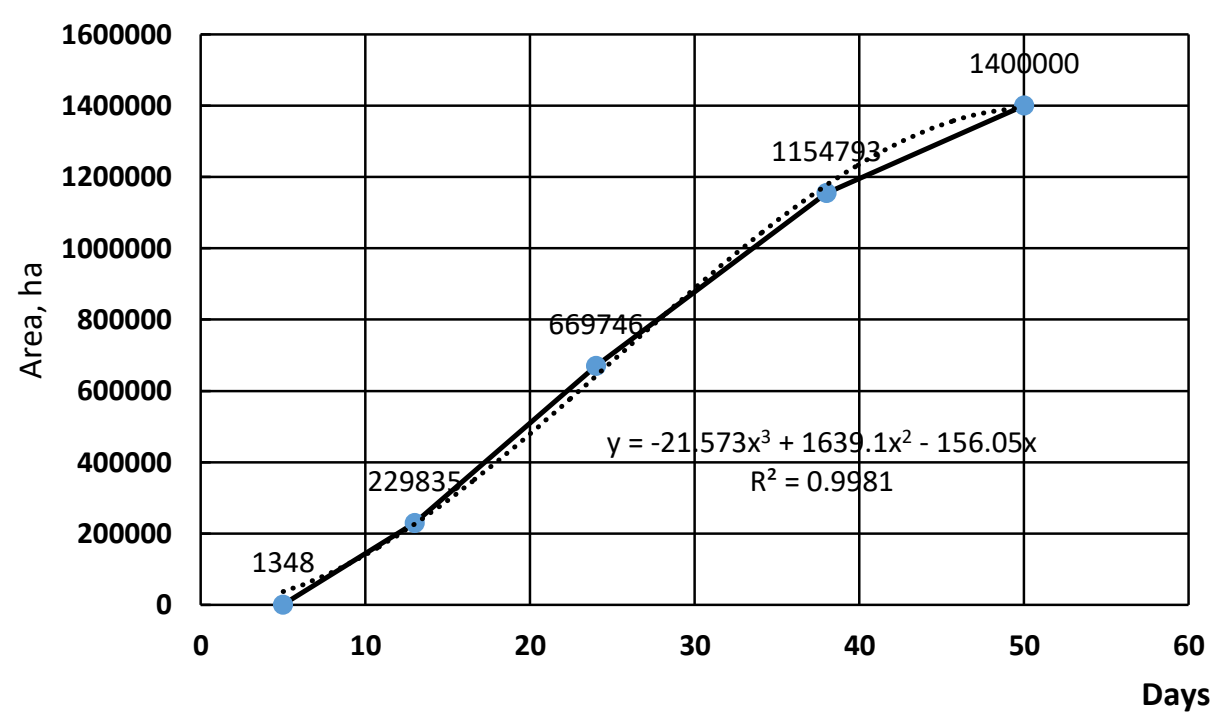

Fig. 7. Indicators of soybean threshing by days of harvest, $t$ (2017). 


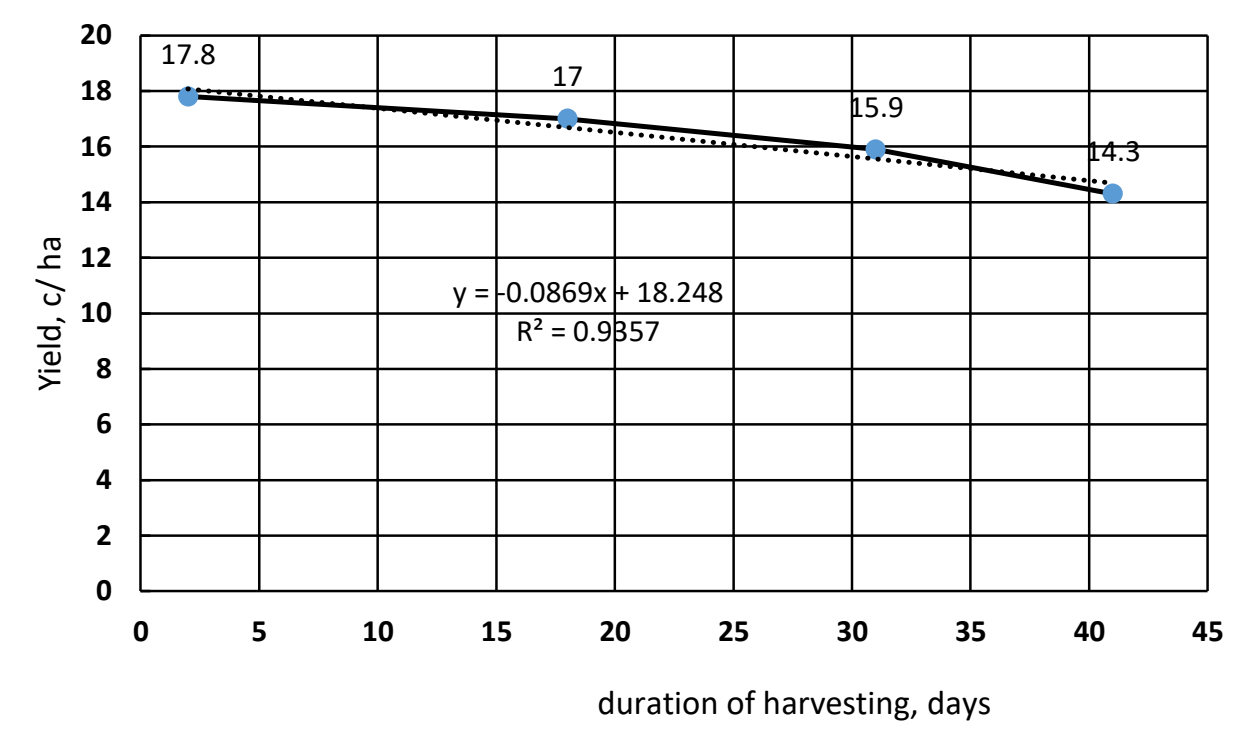

Fig. 8. Soybean yields in the Amur Region, depending on the duration of harvesting, c/ha (2017).

Compliance with the optimal timing in the shortest possible period of sowing and harvesting soybeans in the Amur Region is impossible without the introduction of highperformance equipment. Nowadays, real load on one harvester is 350 hectares (Tambov district) and 640 hectares (Oktyabrsky district) [11]. To optimize the harvesting process, it is necessary to double the fleet of combines, which consists of 2440 units by 01.01.2020.

\section{Discussion}

Soybeans have the largest number of sowing methods, technologies, farming systems that were historically formed in the original focus - Southeast Asia, and developed on the American, European, and Australian continents (Fig. 9).

These include:

- $\quad$ surface profiling - ridges, seedbeds;

- $\quad$ wide-row method (row spacing from 45 to $130 \mathrm{~cm}$ ) of sowing

- $\quad$ one-three row, multi-row, strip sowing;

- $\quad$ using mulch, covering the soil for two harvests;

- $\quad$ blend, compact, mixed sowing;

- $\quad$ cultivation under irrigation and in an arid climate;

- technologies: basic, intensive, adapted, alternative, biologized, innovative;

- technologies of precision farming using: No-till, Mini-till, Strip-till. 


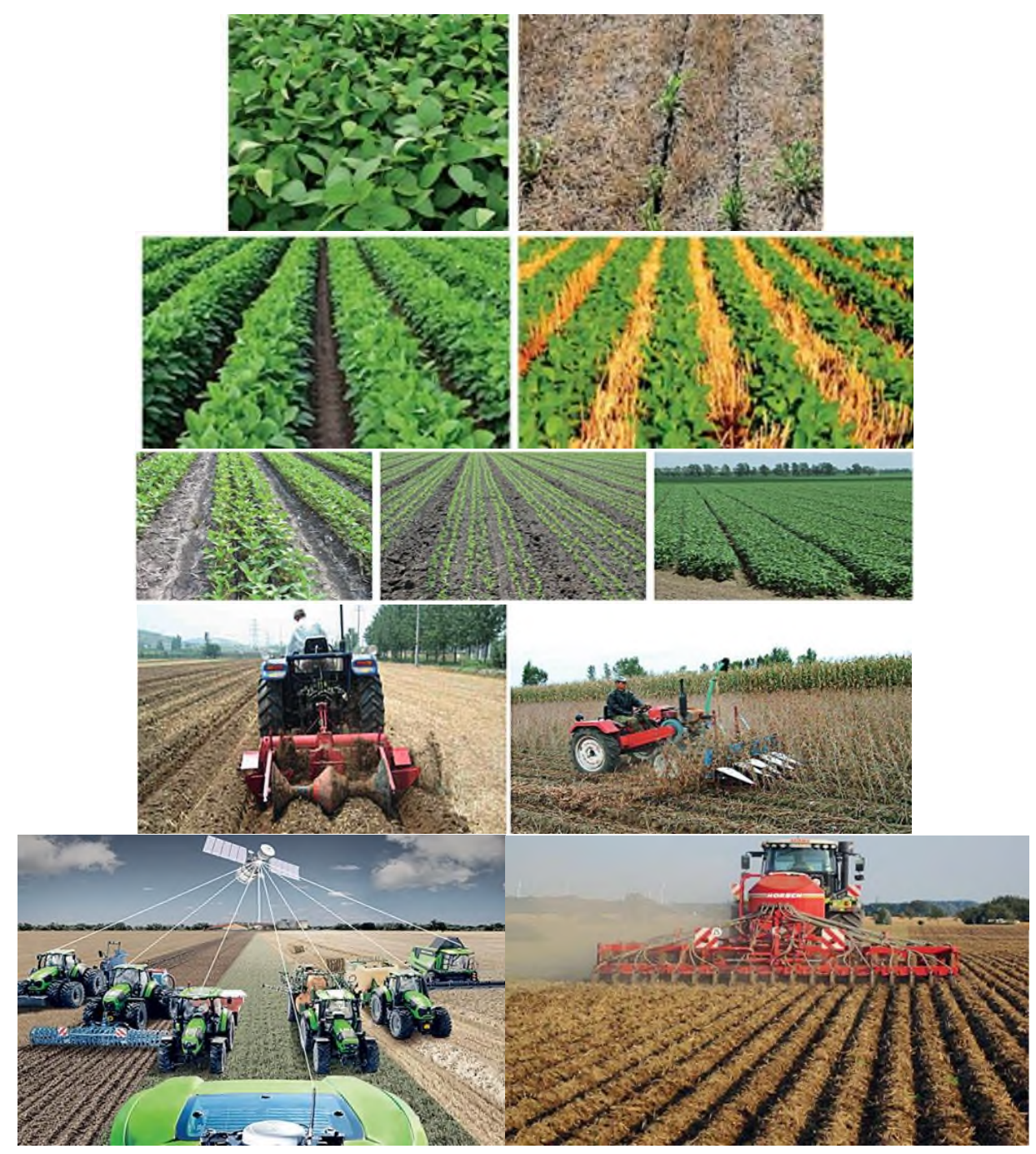

Fig. 9. Methods of sowing soybeans: continuous, wide-row, single and multi-row (rows 1 and 2), ridge-bed technologies (row 3), precision farming system (row 4).

The elements of precision farming introduced in the farms of the Amur Region demonstrate an increase in yield over $2 \mathrm{t} / \mathrm{ha}$. These are the best available technologies (BAT). "Affordable" - have experience in application, can be implemented, technically feasible, economically feasible. "Best" - the most effective for environmental protection. Precision farming technologies are industrial and technological innovations that have become the achievement of world agriculture.

The Ministry of Agriculture of the Russian Federation outlined the agro-technological policy associated with the use of the best available technologies: 1) Programmed harvesting of agricultural crops based on the use of elements of precision farming; 2) Differentiated application of agrochemicals in offline and online modes; 3) The use of high-performance equipment with minimal harmful effects on the soil and the environment.

In Russia, the spread of the best available technologies is hindered by a number of reasons. Great hopes are put on the domestic machine engineering, financially sound 
enterprises. Certain regions, agricultural holdings that have recently started cultivation of soybeans using advanced technologies, receive a soybean yield of more than $2.5 \mathrm{t} / \mathrm{ha}$.

"Biologized technology of potato cultivation" developed in the Far Eastern State Agrarian University is included in the register of the Best basic technology by the Ministry of Agriculture of the Russian Federation (BBT, Rosinformagrotech, 2016) [12]. It is recommended for widespread implementation in the Far Eastern region, obtaining environmentally friendly products, increasing production efficiency. The main elements of biologized BBT can be integrated into basic, progressive technologies for the production of field crops, including soybeans.

For the soil and climatic conditions of the Far Eastern region, the Strip-Till technology can become BAT. It is as close as possible to biological farming, combines elements of classical and energy-saving tillage, reduces the doses of herbicides by 3 times, locally supplying the recommended fertilization rates to the root zone.

In the Amur Region, the technical modernization of the crop production industry is underway, certain elements of GIS technologies are being introduced, but in general, the new technological policy is developing poorly. There are many restraining reasons, and above all, insufficient technical and technological support, which requires significant financial investments in production.

\section{Conclusions}

An increase in the efficiency of soybean production in the Amur Region is possible with a change in technology, the introduction of technical and technological innovations, an increase in the professional training of specialists, and financial support from the state.

\section{References}

1. O.V. Shchegorets Soybean production, monograph. Second revised and enlarged edition - Krasnoznamensk: Paradise Printing House LLC, 600 (2018)

2. Sectoral program of the Russian Soy Union "Development of the production and processing of soybeans in the Russian Federation for 2015-2020» 85 (2014).

3. P.V. Tikhonchuk The farming system of the Amur Region: production and practical guid of Agriculture, 570 (2016)

4. O.V. Shchegorets, N.D. Kumskova, S.V. Gorshkov Cultivation of oil flax as an innovative project for the diversification of crop production in the Amur Region Far Eastern Agrarian Bulletin. 1 (25), 22-26 (2013)

5. O.V. Shchegorets, S.I. Vologdin Prospects for the cultivation of drug-free cannabis in the Amur Region Agricultural industry problems and prospects All-Russian scientific and practical conference, 83 (2020)

6. Strategy of innovative development of the agricultural industry of the Russian Federation for the period up to 2020

7. V. A. Zolotnitsky Soya in the Far East. - Khabarovsk: Book publishing house 248 (1962).

8. V.M. Penchukov, G.K. Skroders, G.K. Shelevoy Ridge crops of soybeans in the Amur region. 90 (1973)

9. P.V. Tikhonchuk, Ecological bases of mobilization of soybean genetic resources: monograph Blagoveshchensk: Publishing house of DalGAU, 177 (2004)

10. I.V. Bumbar Soybean harvesting: monograph Blagoveshchensk (2006) 
11. Ministry of Agriculture of the Amur Region

12. V. Akberdina, L. Pushkareva, Proceedings of the 4th International Conference on Social, Business, and Academic Leadership (ICSBAL 2019) doi:10.2991/icsbal19.2019 .3 